\title{
Performers, Composers, Scores and Editions: Commentary on Huisman, Gingras, Dhondt, and Leman (2017)
}

\author{
DOROTTYA FABIAN[1] \\ School of the Arts and Media, UNSW Sydney
}

\begin{abstract}
Reflecting on a study that examines the impact of various editions on the speed of learning and performance errors, this short paper notes the crudeness of western music notation and how musicians cope with deciphering the composer's musical intentions. Drawing on parallels with practitioners who specialize in historically informed performance and tend to favor playing from manuscripts and facsimiles, I argue that although performing editions are useful, proper education regarding the meaning of notation practices and compositional styles might better serve musicians. This enables each generation to construct its own understanding of the music, and of the contradictory and insufficiently specified demands of the score.
\end{abstract}

Submitted 2016 April 20; accepted 2016 July 21.

KEYWORDS: editions, score reading, historical performance practice, music notation

THE paper by Lukas Huisman and colleagues raises important issues not limited to complex modernist compositions. As is well known, western music notation is a crude system, accurately indicating pitches only as long as they belong to the twelve chromatic pitch-classes commonly used by equal tempered western instruments. Everything else is approximate or not specified. Musicians are well aware that tempo and character words such as vivace or dolce are suggestive and allow for a variety of interpretations. With the rise of the historically informed performance (HIP) practice movement musicians have also become aware that the same articulation signs might call for different ways of execution depending on the style period of compositions or the habits of particular composers. The fact that rhythm notation is also approximate - to a greater or lesser extent, depending on, again, compositional style and period conventions - is a less wellrecognized matter.

The problem of notating rhythm is particularly noteworthy in improvised and polyphonic music; for instance when performing written out ornaments or fugal textures where the polyphonic "theory" goes beyond the instrument's physical capabilities. To my mind, Sorabji's Clavicembalisticum exemplifies both instances. The authors' assertion regarding Sorabji's "impatience with notation" and attitude to performers as well as the editions of his scores could indeed be indicative of a practice that is somewhat similar to Chopin's - a notation that approximates one possible version of execution.[2] The Coda-Stretta example (Huisman et al, Figure 1) may reflect an allusion to the baroque practice of improvised flourishes at cadenzas. The notation here may reflect the "audiated" gesture or effect, disregarding the rules of meter and the number of beats required in the bar. Forcing these into correct metric units through re-notation could mislead the performer regarding the potential musical character intended by the composer. Similar issues could arise in the fugal movement / excerpt. The notated values may relate to the theoretically correct voice-leading, but in practice, the task is to make the polyphony audible, to create aurally perceivable voices. Here a fingering promoting this goal seems like a good idea. It is an interesting finding that the participating pianists opted, instead, for fingering that helped them play the notes - the vertically correct texture. I wonder if the score's rhythm could have been changed slightly to encourage linear thinking.[3] When a score is full of conflicting tuplets, one wonders if the composer wanted a precision that perhaps only machines can achieve, or rather, attempted to notate a sound world that "floats" in non-symmetrical, un-measured rubato that has to be felt rather than counted. Too much focus on correct synchronization again could counteract the musical intention.

All this is, of course, speculation, although legitimate and reasonable speculation. Apparently "some performers doubt the necessity for a correct sonic realization of all pitches and rhythms notated in Sorabji's scores" while others, "most of the current generation of piano performers", aim for "an exact realization of the scores" (Huisman et al, 62). It would have been interesting to see names for both instances as this change 
of attitude could reflect broader tendencies in changing performance styles. Are pianists in the former group of an older generation as implied by the "current generation" descriptor of the second group? As much research on performance style evidenced in sound recordings has shown, musicians born before the First World War had a much more malleable approach to scores, especially to rhythm, which they freely manipulated to point up textural, harmonic, melodic or structural moments (Philip, 2004; Cook, 2014). The modernism of Sorabji might not be that far from the impressionism of Debussy or the romanticism of Chopin, Alkan or Scrjabin. The question of how to read his scores is pertinently related to these broader aesthetic issues, as hinted at by Huisman and colleagues. And so the experiment also partly taps into the current mindframe of musicians and their conventional approach to scores.

An interesting follow-up study would be to test whether re-scoring or "re-education" is a more efficient method for speeding up the learning process and helping to eliminate errors. After all, by now HIP specialists prefer to perform from autograph facsimile scores rather than Urtext or Performing Editions. Some composers also continue to prefer handwriting their music, and complain when they have to use notation software as they feel it "regiments" and "impersonalizes" their way of hearing the music.[4] Is it not that musicians internalize the "meaning" of a composition when they have to decipher it, when they have to go behind the notes and the image of the score? They might just need assistance with learning how to read Sorabji's notation. Alternatively, the number of errors the researchers noted regardless of edition used might decrease if they control for practice time. It seems that the Performance and Study scores sped up learning so under these conditions the participants practiced for shorter periods. If they have to practice for the same amount of time as with the Urtext edition, they might achieve better results in terms of errors.

Given the crudeness of music notation-something that is easier to realize when one attempts to transcribe a performance than when one performs from a score - it is really questionable why we hold on to the primacy of the notated text and give such importance to accuracy in performance. Already Adorno noted that "neither the score nor the performance is in fact the actual "work" (cited in Sarlo, 2010, 21). While the score carries within it "infinite potential performances (...), no particular realization (...) can fully meet the contradictory demands of the work as score" (Paddison, 1993, 197). As I have argued elsewhere, "these contradictory demands of the score speak differently to diverse generations, leading to a variety of performance styles and interpretative approaches" (Fabian, 2015, 44).

Editions, especially performance editions, are helpful, but they reflect a particular performereditor's (or historical period's) understanding of the composer's notation. Ultimately, performers have to return to the composer's version and make it their own so that they can communicate it directly to the audience.

\section{NOTES}

[1] Correspondence can be addressed to d.fabian@unsw.edu.au

[2] The geographically different "first" editions of Chopin's piano pieces, all overseen by the composer, show many variations and discrepancies across identical works making it practically impossible to decide which might be the "original" or "final" version he envisioned. The online Chopin Variorum enterprise (http://www.chopinonline.ac.uk/ocve/) encourages performers to create their own version by using any combination of the different "originals".

[3] Such attempts of "embodied notation" have been made in editions of Bach's 6 Sonatas and Partitas for Solo Violin (e.g. Carl Flesch, Edition Peters 1930s). In the fugal movements and elsewhere, Bach often notates longer values that are impossible to execute on a violin while also playing the other prescribed polyphonic voices. Such scores, however, become cluttered with rests and more confusing to read.

[4] For instance, the late Peter Sculthorpe, who used an assistant to create the typesetting from his handwritten scores (personal communication with composer John Peterson, Sculthorpe's assistant in the late 1990s). 


\section{REFERENCES}

Cook, N. (2014). Beyond the Score. New York: Oxford University Press. https://doi.org/10.1093/acprof:oso/9780199357406.001.0001

Fabian, D. (2015). A Musicology of Performance: Theory and Method Based on Bach's Solos for Violin. Cambridge: Open Book Publishers. https://doi.org/10.11647/OBP.0064

Huisman, L., Gingras, B., Dhondt, G., and Leman, M. (2017). Musical Complexity and 'Embodied Notation': A Study of Opus Clavicembalisticum (K.J. Sorabji). Empirical Musicology Review 12(1-2), 59-71. https://doi.org/10.18061/emr.v12i1-2.4966

Paddison, M. (1993). Adorno's Aesthetics of Music. Cambridge: Cambridge University Press. https://doi.org/10.1017/CBO9780511549441

Philip, R. (2004). Performing Music in the Age of Recording. New Haven: Yale University Press.

Sarlo, D. (2010). Investigating Performer Uniqueness: The Case of Jascha Heifetz. Unpublished doctoral dissertation, Goldsmith College, University of London. 